\title{
Measuring patients' attitudes to care across the primary/secondary interface: the development of the patient career diary
}

\author{
Richard Baker, Carolyn Preston, Francine Cheater, Hilary Hearnshaw
}

\begin{abstract}
Background-A growing number of new ways of organising services across the primary/secondary interface are being introduced and evaluated. The principal motive for such reorganisation is to improve the efficiency of health care. However, unless the impact of the new services on patients is investigated and taken into account, it is possible that patients' reactions could be negative, a factor that could lead to unexpected consequences in the use and costs of services.
\end{abstract}

Objective-To develop a measure of patients' attitudes towards care across the interface between primary and secondary care.

Design-Generation of questions to be included in the measure from a qualitative study of patients' experiences of care across the interface; administration of pilot versions of the measure to samples of patients referred to secondary care; refinement of questions guided by analysis of response patterns, principal components analysis and internal consistency; administration of the final version of the patient career diary in complete form retrospectively to patients referred to secondary care, and one section alone to patients attending outpatient departments for follow up appointments. Face validity was assessed by analysis of open comments in a sample of 50 diaries, and review of the diary by 34 health professionals. Construct validity was assessed by investigation of levels of correlation between components of each section of the diary and the components of the healthcare section overall.

Setting-In the final field test, patients were attending various hospital services, including cardiology, dermatology, neurology, gynaecology, general surgery, general medicine, ophthalmology, trauma and orthopaedics, and gastroenterology. Results-The final version of the diary included 109 questions in seven sections: general practitioner (GP) visits and referral, other GP visits, first outpatient visit, other outpatient visits, inpatient stay and discharge, care after discharge, and care overall. Response rates were poor for retrospective completion of the entire diary, but excellent when a section was given separately. Principal components analysis confirmed that components relating to issues identified as important to patients in the qualitative study had been included in the diary. Levels of internal consistency were good, and comments of patients and health professionals supported validity.

Conclusion-The patient career diary is a valid and reliable measure of patients' attitudes to care across the interface. It should be given in sections to ensure adequate response rates, and is suitable for use in the evaluation or quality of patterns of care across the interface. In future, the impact on patients of new ways of organising services across the interface should be investigated by use of measures such as the patient career diary.

(Quality in Health Care 1999;8:154-160)

Keywords: patient career diary; primary/secondary care interface; measuring patients' attitudes

In almost all developed countries, pressure to improve the efficiency of healthcare services has stimulated interest in the interface between primary and secondary care. By transferring the care of some patients to primary care, costs might be reduced. New patterns of care across the interface, such as shared care, modified systems for referral, or early discharge schemes might enable more patients to receive care but at the same total cost. Managed care and commissioning can be regarded as healthcare policies that aim to improve control of the interface through use of these and other approaches. ${ }^{1}$ In some respects, integrated care may be regarded as a further development of this trend. ${ }^{2}$

At the same time, pressure has also grown from patients and the public for their perspectives to be taken into account in the provision and planning of care, including care across the interface between primary and secondary care. In the UK, this is reflected in plans for increased patient involvement in discussions about the development of services, and the national survey of patient and carer experience. $^{2}$

In the development of new patterns of care across the interface, patients' perspectives have sometimes been assessed. It is important, however, that valid methods of measuring patients' perspectives are used to prevent the wide adoption of a new service that many patients would regard as worse. The consequences of providing a service that patients regard as worse are uncertain, but might include an 
increase in complaints and recourse to alternative less appropriate sources of care.

Several methods may be used to investigate patients' perspectives, including interviews, focus groups, and questionnaires. Each method has advantages and disadvantages. Qualitative methods can provide detailed insight, but are impractical for use with large patient samples. Questionnaires are less costly to administer, but their development is complex if they are to be valid and reliable. This difficulty can be avoided if a suitable questionnaire has already been developed and evaluated. To our knowledge, no such instrument appropriate for use in the $\mathrm{UK}$ is available that can be used for evaluation of care across the primary/secondary interface. In this article we report the development and initial evaluation of an instrument for this purpose-the patient career diary. The diary format was chosen because care across the interface usually takes place in stages, consisting of a series of events in different care settings at different times. The diary would enable patients to express their views of care at each stage.

In addition to the choice of method, it is also important to decide what is to be measured. Satisfaction has been criticised because of the lack of an adequate theory to explain it, ${ }^{3}$ but theories about alternatives such as "opinions" or "views" are even less well developed. In this study therefore, attitudes were chosen as the object of measurement, attitude being defined as "a psychological tendency that is expressed by evaluating a particular entity with some degree of favour or disfavour". ${ }^{4}$ Different patients may have different attitudes towards different aspects of care, and therefore in developing a measure, the aspects of care of most importance to most patients must be identified. In a previous study, we identified the concept of "limbo" or progress through the healthcare system as the key aspect of care ${ }^{5}$ and therefore the patient career diary should include measurement of this concept.

\section{Methods}

IDENTIFICATION OF QUESTIONS

We defined care across the interface as beginning at the point of referral from a general practitioner, and including outpatient, inpatient, and post-discharge care. The issues important to patients were identified through a qualitative study involving a sample of patients who had experienced care across the interface, supplemented by a review of published studies ${ }^{5}$ The literature search was undertaken using Medline, CINAHL, and BIDS (1982-95), and ABI-Inform (1986-95). The search terms included patient satisfaction, attitudes, views, managed care, interface, referral, case management, patient care team, and multidisciplinary. All types of study design were included. Additional articles were identified from reference lists of articles already obtained. Issues identified included access to care, ${ }^{67}$ information given to patients, ${ }^{8}$ the staff-patient relationship, ${ }^{9}{ }^{10}$ continuity of care,${ }^{11}{ }^{12}$ medical care or outcomes, ${ }^{13}$ and environment. ${ }^{14}{ }^{15}$ However, most of these studies were undertaken in single healthcare settings such as inpatient care or general practice, and few had specifically explored care across the interface.

Full details of the qualitative study have been reported. ${ }^{5}$ Briefly, 33 patients attending different services and at different stages in care, and eight carers, took part in focus groups or indepth interviews. These were audiotaped, transcribed, and analysed to identify the underlying issues. The issues that emerged were categorised into five groups: getting in (gaining access to health professionals or services), fitting in (the extent to which the service fitted in with the patient's requirements, and the extent to which the patient had to fit in with the healthcare system), knowing what's going on (the provision of information at all stages of care), continuity (seeing the same professionals and consistency of management), and limbo (failure to progress through the system). These issues incorporated all those we had identified from previous publications, with the addition of one particularly relevant to care across the interface-limbo.

An initial bank of questions was developed after the literature review and qualitative study, taking into account the issues identified as important. Questions were derived from patients' and carers' remarks, and grouped by stage of care (referral from general practitioner (GP), first outpatient appointment, other outpatient appointments, other visits to the general practitioner, inpatient stay, care during the month after discharge, and healthcare overall). We used a five point Likert response format, with an additional not applicable

Table 1 The sequence of pilot tests

\begin{tabular}{|c|c|c|c|c|}
\hline Pilot and diary content & Setting & No of questions & No of patients & No $(\%)$ response \\
\hline \multicolumn{5}{|l|}{ Pilot 1} \\
\hline $\begin{array}{l}\text { Questionnaire } 1 \\
\text { GP and outpatient visits, healthcare overall }\end{array}$ & $\begin{array}{l}4 \text { NHS trusts and } 4 \\
\text { general practices }\end{array}$ & 110 & 295 & $173(59)$ \\
\hline $\begin{array}{l}\text { Questionnaire } 2 \\
\text { Inpatient care, discharge, healthcare overall }\end{array}$ & & 78 & 239 & $131(56)$ \\
\hline \multicolumn{5}{|l|}{ Pilot 2} \\
\hline $\begin{array}{l}\text { Questionnaire } 1 \\
\text { GP and outpatient visits, healthcare overall }\end{array}$ & $\begin{array}{l}4 \text { NHS trusts and } 5 \\
\text { general practices }\end{array}$ & 107 & 351 & $162(46)$ \\
\hline $\begin{array}{l}\text { Questionnaire } 2 \\
\text { Inpatient care, discharge, healthcare overall }\end{array}$ & & 85 & 291 & $142(49)$ \\
\hline Pilot 3 & & & & \\
\hline $\begin{array}{l}\text { Combined questionnaire } \\
\text { GP visits, outpatient visits, inpatient stay, } \\
\text { discharge, care since discharge }\end{array}$ & $\begin{array}{l}3 \text { NHS trusts and } 2 \\
\text { general practices }\end{array}$ & 121 & 567 & $283(50)$ \\
\hline
\end{tabular}


Table 2 Characteristics of the respondents in field test; $n=601$

\begin{tabular}{ll}
\hline Age & \\
Mean (SD) & $55.4(16.9)$ \\
Range (years) & $16-92$ \\
Sex & \\
Men (\%) & $308(51)$ \\
Women (\%) & $293(49)$ \\
Specialty & $N(\%)$ \\
Cardiology & $31(5)$ \\
Haemotology & $11(2)$ \\
Dermatology & $16(3)$ \\
Neurology & $12(2)$ \\
Urology & $25(4)$ \\
Rheumatology & $11(2)$ \\
Gynaecology & $13(2)$ \\
Ear, nose, and throat & $42(7)$ \\
General surgery & $133(22)$ \\
General medicine & $29(5)$ \\
Ophthalmology & $20(3)$ \\
Trauma and orthopaedics & $37(6)$ \\
Gastroenterology & $10(2)$ \\
Renal/dialysis/nephrology & $15(2)$ \\
Radiology & $27(4)$ \\
Diabetes clinic & $11(2)$ \\
Other & $60(10)$ \\
Not known & $98(16)$ \\
&
\end{tabular}

option. ${ }^{16}$ Likert's method of developing summative rating scales was devised to measure attitudes, and has been widely used for this purpose. ${ }^{4}$ There was a mixture of positively and negatively worded questions.

PILOT TESTS

All stages of the study were approved by Leicestershire, Derbyshire, Lincolnshire, and Birmingham ethical committees. The questions were refined through a series of three pilot tests (table 1). Questionnaires were sent by post to patients referred to by GPs to NHS trusts. We included all types of patients referred to the trusts except emergency admissions, maternity care, terminal care, and children $<16$ years. These groups were excluded because a measure that would be applicable to all groups would have been at risk of becoming either too large and complex, or related to such general aspects of care as to provide only superficial information. These groups of patients were also excluded from the preliminary qualitative study. In the first two pilot tests, two questionnaires were submitted to patients at different stages of care. One questionnaire dealt with care up to hospital admission, and the other looked at care during admission and after discharge. All the pilot questionnaires included open questions inviting comments from patients about their care.

The findings of each pilot test guided the rewording of questions and the replacement of others before a further pilot test. Open comments written by patients were noted, including any indicating difficulty in understanding or responding to the questions. The frequency with which each question was left unanswered by respondents (the missing response rate) was calculated to identify questions that patients found difficult to answer because of ambiguity or other problems. Response patterns were used to identify questions that were answered uniformly positively or negatively, thus failing to detect a range of attitudes. The initial qualitative study had identified the issues that should be included, and therefore principal components analysis with Varimax rotation was used to check that no issues had been omitted. ${ }^{17}$ It was also used to identify questions that did not relate clearly to one or other of the issues. Internal consistency reliability was tested using Cronbach's $\alpha .^{18}$

FIELD TEST

After the pilot tests, a full version of the diary was developed that included the refined questions. The diary included a total of 109

Table 3 Scores for each section of the diary, and each component within sections

\begin{tabular}{|c|c|c|c|c|c|}
\hline & $a$ & Mean $(S D)$ & Min & $\operatorname{Max}$ & $N$ \\
\hline \multicolumn{6}{|c|}{ Section 1: when the GP told you that you needed to go to the hospital/specialist clinic } \\
\hline Component 1 (fitting in, information) & .83 & $66.0(19.4)$ & 10.7 & 100.0 & 414 \\
\hline Component 2 (getting in, appointments) & .79 & $71.7(21.1)$ & 6.3 & 100.0 & 482 \\
\hline Component 3 (continuity) & .81 & $67.9(25.1)$ & 0 & 100.0 & 454 \\
\hline \multicolumn{6}{|c|}{ Section 2: other visits to the GP surgery (in connection with your hospital/clinic visits) } \\
\hline Component 1 (information, fitting in) & .82 & $67.4(22.7)$ & 6.3 & 100.0 & 189 \\
\hline Component 2 (getting in, appointments) & .80 & $72.2(20.0)$ & 0 & 100.0 & 223 \\
\hline Component 3 (communication between hospital and GP, information) & .75 & $73.3(17.3)$ & 18.8 & 100.0 & 179 \\
\hline Component 4 (continuity, choice of doctor) & .77 & $73.4(21.2)$ & 0 & 100.0 & 213 \\
\hline \multicolumn{6}{|l|}{ Section 3: going to your first outpatient or specialist clinic visit } \\
\hline Component 1 (information, fitting in) & .90 & $63.7(21.3)$ & 9.4 & 100.0 & 421 \\
\hline Component 2 (continuity, choice of doctor) & .83 & $58.7(10.4)$ & 16.7 & 100.0 & 392 \\
\hline Component 3 (getting in) & .78 & $57.4(24.7)$ & 0 & 100.0 & 440 \\
\hline Component 4 (clinic organisation) & .66 & $69.4(17.1)$ & 12.5 & 100.0 & 448 \\
\hline Component 5 (limbo) & .57 & $54.2(21.1)$ & 0 & 100.0 & 450 \\
\hline \multicolumn{6}{|l|}{ Section 4: other outpatient or specialist clinic visits } \\
\hline Component 1 (information, fitting in) & .93 & $68.2(20.0)$ & 13.9 & 100.0 & 154 \\
\hline Component 2 (continuity, choice of doctor) & .78 & $54.6(19.8)$ & 10.0 & 100.0 & 119 \\
\hline Component 3 (appointment, wait for appointment) & .66 & $65.9(19.6)$ & 8.3 & 100.0 & 163 \\
\hline Component 4 (receptionists) & .72 & $74.3(18.9)$ & 0 & 100.0 & 188 \\
\hline \multicolumn{6}{|c|}{ Section 5a: your hospital stay: going into hospital, your stay on the hospital ward, and coming out of hospital } \\
\hline Component 1 (continuity, information) & .89 & $58.2(23.1)$ & 0 & 100.0 & 219 \\
\hline Component 2 (fitting in, information) & .83 & $68.7(22.5)$ & 0 & 100.0 & 266 \\
\hline Component 3 (wait for admission) & .81 & $62.9(22.9)$ & 0 & 100.0 & 218 \\
\hline Component 4 (discharge) & .87 & $67.6(24.6)$ & 0 & 100.0 & 252 \\
\hline \multicolumn{6}{|c|}{ Section 5b: your hospital stay: your care during the month after you came out of hospital } \\
\hline Whole section & .91 & $59.1(23.3)$ & 0 & 100.0 & 219 \\
\hline \multicolumn{6}{|l|}{ Section 6: your health care overall } \\
\hline Component 1 (coordination, progress) & .88 & $67.1(22.4)$ & 0 & 100.0 & 421 \\
\hline Component 2 (continuity, limbo) & .84 & $55.6(22.6)$ & 0 & 100.0 & 377 \\
\hline
\end{tabular}

$\mathrm{N}=$ total number of patients responding to all questions in each component. The scores are for scales with a possible minimum of 0 and a maximum of 100 .

$\alpha=$ Cronbach's $\alpha$. 


\begin{tabular}{|c|c|c|c|}
\hline & & Primary component & $\begin{array}{l}\text { Loadings }>0.4 \text { on other } \\
\text { components }\end{array}$ \\
\hline \multicolumn{4}{|c|}{ Component 1 (information, fitting in) } \\
\hline Q19 & The doctor always gave me a lot of support & (C1) -0.766 & \\
\hline Q17 & Sometimes I felt that the doctor did not see my condition as being very important & (C1) 0.747 & \\
\hline $\mathrm{Q} 20$ & I got enough advice on how to look after myself & (C1) -0.727 & \\
\hline Q21 & I came away from outpatient/specialist clinic appointments with some of my questions unanswered & (C1) 0.702 & \\
\hline Q14 & I sometimes felt that the doctor was not very good at listening to me & (C1) 0.698 & \\
\hline Q18 & I felt I had enough time to discuss my condition during my consultation & (C1) -0.653 & \\
\hline Q15 & The doctors did not fully involve me in decisions about my care & (C1) 0.629 & (C2) 0.403 \\
\hline Q16 & Sometimes I could not completely understand what the doctor told me & (C1) 0.569 & (C2) 0.430 \\
\hline \multicolumn{4}{|c|}{ Component 2 (continuity, choice of doctor) } \\
\hline Q11 & It was difficult to get to see the doctor of my choice & (C2) 0.840 & \\
\hline Q12 & I had to see junior doctors when I wanted to see the consultant doctor & (C2) 0.806 & \\
\hline Q10 & I saw the doctor that I needed to see & (C2) -0.729 & \\
\hline \multicolumn{4}{|c|}{ Component 3 (getting in) } \\
\hline Q3 & It was easy to get an appointment quickly at the outpatient/specialist clinic & (C3) 0.839 & \\
\hline Q6 & $\begin{array}{l}\text { I didn't have to wait too long before I went to my first appointment at the outpatient/ specialist } \\
\text { clinic }\end{array}$ & (C3) 0.808 & \\
\hline Q4 & $\begin{array}{l}\text { I was kept informed of what was happening in between being told that I would need to go to the } \\
\text { outpatient/specialist clinic, and going to my first appointment }\end{array}$ & (C3) 0.659 & \\
\hline \multicolumn{4}{|c|}{ Component 4 (clinic organisation) } \\
\hline Q8 & The receptionists sometimes could make me feel that I was not important & (C4) 0.817 & \\
\hline Q7 & I always felt that the receptionists were very helpful & (C4) -0.781 & \\
\hline Q13 & I would have preferred a little more privacy in the outpatient/specialist clinic & (C4) 0.443 & (C2) 0.411 \\
\hline \multirow{2}{*}{\multicolumn{4}{|c|}{ Component 5 (limbo) }} \\
\hline & & & \\
\hline Q2 & $\begin{array}{l}\text { Once I was told that I would need to go to the outpatient/specialist clinic, I felt that I was "out of } \\
\text { the hands" of the GP }\end{array}$ & (C5) 0.785 & \\
\hline Q1 & I felt I was left "in limbo" after I was told that I would need to go to the outpatient/specialist clinic & (C5) 0.679 & \\
\hline Q5 & $\begin{array}{l}\text { I didn't know how long I would have to wait for my first appointment at the outpatient/specialist } \\
\text { clinic }\end{array}$ & (C5) 0.460 & \\
\hline
\end{tabular}

closed questions: 14 about GP visits and referral; 21 about the first outpatient visit; 19 about other outpatient visits; 18 about inpatient stay and discharge; nine about care in the time since coming out of hospital; 15 about other GP visits; and 13 about healthcare overall. Some questions were repeated across sections. At the end of each section there was an opportunity for patients to add further comments. The diary also included open sections that invited patients to record events during their care such as admissions or outpatient consultations, and also to note their reactions. A similar open section was also included for carers.

This full version of the diary was evaluated in a field test. The diary may be completed prospectively at each stage of care provided that the duration of the study is sufficient for care across the interface to be completed. It may also be completed retrospectively, and because only a short period was available for the field test, patients were asked to complete the diary retrospectively.

Patients were recruited from various settings in four health authority areas. In one health authority they were identified in seven general practices from lists of referrals made in the previous five months. In the other health authorities they were identified from lists of patients attending their first outpatient appointment or those discharged up to three months previously. The hospitals involved in this phase were a city, teaching hospital; a city, non-teaching hospital; and a non-teaching hospital in a moderate sized town. The diary was posted to 1814 patients. Reminders and another copy of the diary were sent approximately one month later, second reminders being sent after a further two weeks.

In routine use, it may be more appropriate to give single sections or a small selection of sec- tions rather than the entire diary. Therefore, to test the patient response rate to giving the diary in sections, the follow up outpatient section was issued by a researcher to a consecutive sample of 105 patients attending orthopaedics, nephrology, cardiology, and urology outpatients. Patients were asked to complete the questionnaire and return it before leaving the outpatient department. No reminders were sent to these patients.

\section{ANALYSIS}

All data were entered into SPSS Version 6 for analysis. The responses to each question were scored from 1 to 5, depending on the level of agreement with the question statements. The scores were reversed when appropriate to produce a standard system in which 5 indicated a positive attitude, and 1 a negative attitude.

As in the pilot tests, principal components analysis was used to identify groups of questions that addressed underlying issues, and Cronbach's $\alpha$ was used to test internal consistency. Scores were calculated for the identified components by transforming the sum of the scores of the questions in each component to a zero to 100 scale, 100 being the most positive and zero the most negative.

Content validity was assessed through analysis of the patients' open comments in a random sample of 50 completed diaries to check that no questions about important aspects of care had been omitted from the diary. Content validity and acceptability were also assessed by submitting the diary to 34 health professionals and requesting their comments. The professionals were identified from local acute hospitals, community and mental health trusts, health authorities, and general practices that had expressed interest in the diary or had assisted in the pilot tests. 
Table 5 Numbers of patients indicating responses to each question of section 3 (first outpatient of specialist clinic visit; $n=511$ )

\begin{tabular}{|c|c|c|c|c|c|c|c|c|}
\hline & & $\begin{array}{l}\text { Strongly } \\
\text { agree }\end{array}$ & Agree & Neutral & Disagree & $\begin{array}{l}\text { Strongly } \\
\text { disagree }\end{array}$ & $N / A$ & Missing \\
\hline Q1 & $\begin{array}{l}\text { I felt I was left "in limbo" after I was told that I would } \\
\text { need to go to the outpatient/specialist clinic }\end{array}$ & 18 & 75 & 72 & 235 & 76 & 12 & 23 \\
\hline Q2 & $\begin{array}{l}\text { Once I was told that I would need to go to the } \\
\text { outpatient/specialist clinic, I felt that I was "out of } \\
\text { the hands" of the GP }\end{array}$ & 39 & 151 & 63 & 175 & 55 & 11 & 17 \\
\hline Q3 & $\begin{array}{l}\text { It was easy to get an appointment quickly at the } \\
\text { outpatient/specialist clinic }\end{array}$ & 69 & 212 & 67 & 107 & 37 & 8 & 11 \\
\hline Q4 & $\begin{array}{l}\text { I was kept informed of what was happening in } \\
\text { between being told that I would need to go to the } \\
\text { outpatient/specialist clinic, and going to my first } \\
\text { appointment }\end{array}$ & 51 & 148 & 67 & 144 & 41 & 36 & 24 \\
\hline Q5 & $\begin{array}{l}\text { I didn't know how long I would have to wait for my } \\
\text { first appointment at the outpatient/specialist clinic }\end{array}$ & 54 & 210 & 45 & 128 & 39 & 16 & 19 \\
\hline Q6 & $\begin{array}{l}\text { I didn't have to wait too long before I went to my first } \\
\text { appointment at the outpatient/ specialist clinic }\end{array}$ & 85 & 252 & 35 & 86 & 31 & 10 & 12 \\
\hline Q7 & I always felt that the receptionists were very helpful & 115 & 289 & 60 & 27 & 6 & 3 & 11 \\
\hline Q8 & $\begin{array}{l}\text { The receptionists sometimes could make me feel that } \\
\text { I was not important }\end{array}$ & 9 & 40 & 62 & 261 & 99 & 9 & 31 \\
\hline Q9 & $\begin{array}{l}\text { I did not have to wait too long in the outpatient/ } \\
\text { specialist clinic }\end{array}$ & 82 & 266 & 29 & 87 & 22 & 2 & 23 \\
\hline Q10 & I saw the doctor that I needed to see & 116 & 278 & 33 & 39 & 10 & 15 & 20 \\
\hline Q11 & It was difficult to get to see the doctor of my choice & 9 & 45 & 78 & 200 & 74 & 71 & 34 \\
\hline Q12 & $\begin{array}{l}\text { I had to see junior doctors when I wanted to see the } \\
\text { consultant doctor }\end{array}$ & 24 & 61 & 69 & 198 & 81 & 41 & 37 \\
\hline Q13 & $\begin{array}{l}\text { I would have preferred a little more privacy in the } \\
\text { outpatient/specialist clinic }\end{array}$ & 20 & 55 & 73 & 235 & 87 & 16 & 25 \\
\hline Q14 & $\begin{array}{l}\text { I sometimes felt that the doctor was not very good at } \\
\text { listening to me }\end{array}$ & 29 & 72 & 41 & 212 & 113 & 14 & 30 \\
\hline Q15 & $\begin{array}{l}\text { The doctors did not fully involve me in decisions } \\
\text { about my care }\end{array}$ & 28 & 67 & 62 & 211 & 90 & 21 & 32 \\
\hline Q16 & $\begin{array}{l}\text { Sometimes I could not completely understand what } \\
\text { the doctor told me }\end{array}$ & 23 & 107 & 39 & 217 & 83 & 13 & 29 \\
\hline Q17 & $\begin{array}{l}\text { Sometimes I felt that the doctor did not see my } \\
\text { condition as being very important }\end{array}$ & 30 & 65 & 44 & 234 & 91 & 14 & 33 \\
\hline Q18 & $\begin{array}{l}\text { I felt I had enough time to discuss my condition } \\
\text { during my consultation }\end{array}$ & 94 & 258 & 26 & 81 & 17 & 10 & 25 \\
\hline Q19 & The doctor always gave me a lot of support & 94 & 192 & 102 & 64 & 14 & 17 & 28 \\
\hline Q20 & I got enough advice on how to look after myself & 75 & 222 & 76 & 70 & 20 & 22 & 26 \\
\hline Q21 & $\begin{array}{l}\text { I came away from outpatient/specialist clinic } \\
\text { appointments with some of my questions } \\
\text { unanswered }\end{array}$ & 35 & 135 & 47 & 191 & 61 & 14 & 28 \\
\hline
\end{tabular}

$\mathrm{N} / \mathrm{A}=$ indicated by patients as inapplicable. Missing = question not answered.

\section{Results}

PILOT TESTS

During the pilot tests, groups of questions (components) emerged that were related to the issues identified in the literature and patient interviews. The elimination of some questions and the rewording or addition of others reduced the tendency for generally positive responses to predominate. Respondents' open comments did not indicate that any issue had been overlooked by the diary questions, although response rates were relatively low (table 1). At the conclusion of the pilot tests, a complete version was ready for evaluation.

FIELD TEST

Of the 1814 patients, 161 were excluded because their first outpatient appointment did not take place within the time scale of the study. A total of 601 patients completed the diary (36.4\% of the sample). The mean age of the responders was 55.4 years, and the mean age of the non-responders was 53.2 (Mann Whitney test $\mathrm{p}<0.01)$. There was no significant difference, however, between responders and non-responders for sex or specialty of attendance. The responders included patients referred to various specialties and they had a wide age range (table 2). The response rate when a single section of the diary was issued alone was much higher. In total, 97 (92\%) patients returned the follow up outpatient section.
The analysis was based on 601 patients participating in the field test. For each section of the diary, principal components analysis indicated that the underlying issues identified as important to patients had been addressed (table 3). Although different issues influenced patients' attitudes at different stages in care, the diary as a whole did address the issues identified as important to patients. For example, questions about access to care and obtaining a referral were more likely to form a distinct component concerned with "getting in" in sections relating to general practice. At the first outpatient visit, the wait for the appointment became the predominant issue within the more general concept of "getting in", and for inpatient care the wait for admission emerged as dominant. The analysis also suggested that patients' attitudes towards receiving information and the relationship with caregivers are closely linked. Principal components analysis of the follow up outpatient section responses identified similar components when the questionnaire was given alone or as part of the diary. Table 4 shows the results of principal components analysis for the first outpatient section. The findings relating to this section of the diary were typical of those for the other sections, and details of these are available from the authors.

Table 3 shows levels of $\alpha$ for each component of each section, and most fall within the recommended range of 0.7 to $0.9 .^{18}$ The components attracted a wide range of scores (table 3 ) and the 
Table 6 Scores for components of sections of the diary subsequent to referral, for samples of patients attending two hospitals

\begin{tabular}{|c|c|c|c|}
\hline Section & $\begin{array}{l}\text { Hospital a (no of } \\
\text { respondents) }\end{array}$ & $\begin{array}{l}\text { Hospital b (no of } \\
\text { respondents) }\end{array}$ & $\begin{array}{l}95 \% \text { confidence } \\
\text { interval of difference }\end{array}$ \\
\hline (3) First outpatient clinic & (118) & (91) & \\
\hline Fitting in & 65 & 62 & -2.4 to 8.7 \\
\hline Continuity & 61 & 57 & .1 to 5.9 \\
\hline Getting in & 59 & 62 & -9.9 to 3.8 \\
\hline Organisation & 70 & 65 & -.3 to 9.4 \\
\hline Limbo & 54 & 55 & -6.8 to 5.9 \\
\hline (4) Other outpatient visits & $(51)$ & (39) & \\
\hline Fitting in & 72 & 67 & -3.5 to 12.7 \\
\hline Continuity & 62 & 51 & .8 to 21.4 \\
\hline Getting in & 68 & 68 & -8.4 to 8.2 \\
\hline Receptionists & 74 & 72 & -4.3 to 9.5 \\
\hline (5) Inpatient stay & $(94)$ & $(61)$ & \\
\hline Continuity & 64 & 55 & .4 to 16.5 \\
\hline Fitting in & 71 & 67 & -3.8 to 11.6 \\
\hline Getting in & 66 & 58 & -.4 to 17.0 \\
\hline Discharge & 73 & 68 & -3.4 to 11.9 \\
\hline \multirow[t]{2}{*}{ (5) After discharge } & $(76)$ & $(56)$ & \\
\hline & 66 & 57 & -.2 to 15.8 \\
\hline (6) Care overall & (119) & $(90)$ & \\
\hline Coordination & 68 & 68 & -5.8 to 5.9 \\
\hline Limbo & 59 & 53 & .4 to 12.7 \\
\hline
\end{tabular}

mean coefficient of variation ${ }^{19}$ for all components was $32.5 \%$. Table 5 shows the response patterns for individual questions in the first outpatient visit section. Despite the revisions during the pilot tests, many questions attracted relatively positive responses. However, the response to some suggested that many patients did have criticisms of care, for example question four ("I was kept informed of what was happening in between being told that I would need to go to the clinic and going to my first appointment") and question 21 ("I came away from outpatient appointments with some of my questions unanswered"). In the first outpatient visit section the proportion of patients who failed to answer individual questions varied between questions from $2 \%$ to $7 \%$ (mean $5 \%$ ), suggesting that most patients found the questions easy to understand (table). Table 6 shows the scores of patients attending two of the hospitals in the final field test.

Seventy four per cent of the completed diaries had open comments. To check validity, the open comments in a random sample of 50 diaries were analysed. No issues were identified in the open comments that were not addressed in the diary sections. The health professionals who gave their views on the diary included community and hospital nurses, GPs, specialists, health authority staff, and hospital managers. They did not identify any additional issues to be included in the diary, but suggested that it be adapted for use with a wider range of patients, such as children or those attending accident and emergency departments. It was also suggested that versions be prepared for those from ethnic minority groups and others who have problems with written English.

\section{Discussion}

In this paper we have described the development of a measure of patients' views of care across the interface between primary and secondary care. The findings indicate that patients do have a range of attitudes towards the care they receive when referred across the interface. Some patients hold particularly negative attitudes towards important aspects of care such as the information they receive, their relationship with healthcare professionals, and the progress they make through the system.

The findings also provide evidence for reliability, and indicate that the diary is sufficiently sensitive to detect negative attitudes about aspects of care, including the detection of differences between samples of patients attending different hospitals. The diary has also been shown to have content validity. It also addresses an issue identified as particularly important to patients who experience care across the interface limbo, or progress through the system towards recovery, or acceptance of an altered state of health. ${ }^{5}$ Additional information about validity from future studies would be desirable, however. Although some other measures of patients' satisfaction or attitudes do address the issues of information, access to care, and continuity, they do not address limbo. Consideration should be given by researchers and health service managers therefore to the use of the diary in studies of existing or new systems of care across the interface.

The response rate to retrospective administration of the diary in its entirety was low, and this method of administration cannot be recommended. Although the response rate may permit assessment of the psychometric properties of the diary, it cannot be used to draw inferences about patients' views of care provided by particular hospitals or practices. Prospective completion is likely to improve response rates provided that patients receive encouragement to continue completing the diary throughout their care. For some groups of patients, care may occur over a prolonged period, and response rates may fall if prospective administration is employed. The diary comprises several short sections, and administration of each section separately at appropriate stages in care achieves a high response rate. For most studies of care across the interface this should be the preferred method.

Use of the diary should not be regarded as a substitute for qualitative methods of investigating patients' perspectives of care across the interface. The diary provides reliable and valid quantitative information, and the open sections also provide responses from patients and carers that give insight into their experiences. These characteristics make the diary suitable for use in studies involving relatively large numbers of patients typical of those included in the pilot and field test. If different groups of patients are included, however, qualitative methods may be required to identify the particular issues important to them. The findings of the qualitative study ${ }^{5}$ undertaken before development of the diary have shown that issues important to patients may not have been identified in previous studies, and therefore they have been omitted from questionnaires.

It is also important to note that the diary does not address the clinical outcome of care. If information about clinical outcome is required therefore, additional instruments should be used. 
Provided these qualifications are noted, the diary can be recommended for further evaluation and use in studies and quality improvement of care across the interface. Patients clearly do have attitudes towards care across the interface, and they can be measured by instruments such as the patient career diary. In future, the use of poor methods of measuring patients' perspectives to services should be avoided, and when new systems of care across the interface are being introduced, it should be obligatory to thoroughly investigate patients' perspectives.

The Clinical Governance Research and Development Unit is core funded by Leicestershire Health Authority, with some initial "pump priming" support from Eli Lilly and Company. Thi study was funded by the NHS research and developmen programme (project PSI 1-26). We are deeply grateful to all the patients who completed versions of the diary or took part in
interviews. We also thank the staff of the NHS trusts and general practices that assisted in recruiting patients.

The study was approved by Leicestershire, Derbyshire, Lincolnshire, and Birmingham ethical committees.

1 Fairfield G, Hunter DJ, Mechanic D, et al. Managed care. Origins, principles and evolution. BMF 1997;314:1823.

2 Department of Health. The new NHS, modern, dependable. London: $\mathrm{DoH}, 1997$.

3 Baker R. A pragmatic model of patient satisfaction: progress towards a theory. Quality in Health Care 1997;6:201-4.

4 Eagly AH, Chaiken S. The psychology of attitudes. Fort Worth: Harcourt Brace College Publishers, 1993.
5 Preston C, Cheater F, Baker R, et al. Left in limbo: patients' views on care across the primary/secondary interface. Quality in Health Care 1999;8:16-22.

6 Bjorkman T, Hansson L, Svensson B, et al. What is important in psychiatric outpatient care? Int $\mathcal{f}$ for Quality in Health Care 1995;7:355-62.

7 Bowers M, Swan J, Koehler W. What attributes determine quality and satisfaction with health care delivery? Health Care Management Review 1994;19:49-55.

8 Delbanco TL. Enriching the doctor-patient relationship by nviting the patient's perspective. Ann Intern Med 1992;116: $414-18$

9 Wilde B, Starri B, Larsson G, et al. Quality of care from a patient's perspective. Scand f Caring Sci 1993;7:113-70.

10 Ware JE, Davies-Avery A, Stewart AL. The measurement and meaning of patient satisfaction. Health and Medical Services Review 1978;1:1-15.

11 Fincham J, Wertheimer A. Predictors of patient satisfaction in a health maintenance organisation. Fournal of Health Care Marketing 1988;6:5-11.

12 Baker R, Whitfield M. Measuring patient satisfaction: a test of construct validity. Quality in Health Care 1992;1:104-9.

13 Meterko M, Rubin H. Patient judgements of hospital quality: taxonomy. Med Care 1990;28(suppl):s10-11.

14 Hall JA, Dornan MC. What patients like about their medical care and how often they are asked: a meta-analysis of the satisfaction literature. Soc Sci Med 1988;27:935-9.

15 Grogan S, Conner M, Willits D, et al. Development of a questionnaire to measure patients' satisfaction with general practitioners' services. Br f Gen Pract 1995;45:525-9.

16 Likert R. A technique for the measurement of attitudes. Arch Psychol 1932;140:1-55.

17 Manley BJF. Multivariate statistical methods: a primer. London: Chapman and Hall, 1986.

18 Streiner DL, Norman GR. Health measurement scales. A practical guide to their development and use. Second edition. Oxford: Oxford University Press, 1995.

19 Armitage P. Statistical methods in medical research. Oxford: Blackwell Scientific Publications, 1971:43. 